ELKOM, Vol.12, No.2, Desember 2019, pp. 72 - 83

p-ISSN : $1907-0012$ (print)

e-ISSN : 2714-5417 (online)

http://ejurnal.stekom.ac.id/index.php/home

- page 72

\title{
IPLEMENTASI MANAJEMEN PENJADWALAN PRODUKSI PADA MESIN SECARA PARALEL DENGAN METODE EARLIEST DUE DATE
}

\author{
Migunani ${ }^{1}$, Danang Nur Cahyo ${ }^{2}$ \\ ${ }^{1}$ Sistem Informasi STMIK ProVisi Semarang \\ migunani@provisi.ac.id \\ ${ }^{2}$ Sistem Informasi STMIK ProVisi Semarang \\ danangnc26@gmail.com
}

\section{ARTICLE INFO}

Article history:

Received 30 November 2019

Received in revised form 2 Desember 2019

Accepted 10 Desember 2019

Available online 12 Desember 2019

\begin{abstract}
The management of production and operations in factory machinery is an optimal management effort in the use of resources consisting of labor, machinery, equipment and raw materials. The production and operations manager directs various inputs in order to produce various outputs or results in units of quantity, quality, price, specific time and location according to consumer demand. Efficiency and effectiveness of the production process to be achieved requires proper scheduling management so that the production output produced can be completed according to target. Management of production and customer orders is still simple, besides that the status of raw material inventories that cannot be directly known can often result in delays in the production process and even production cannot be done as soon as possible. Scheduling orders that enter using the system first in first out where the first order that comes is done, but has not considered the number of orders, priority of customers, maturity of workmanship and engine capacity so that the estimated completion of the order can not be known. To make it more efficient and directed, the Earliest Due Date method is used by sorting the production work based on the closest due date. This method can be used for scheduling on one machine or for scheduling on several machines (parallel machine) so that the scheduling management information system can manage effective production scheduling and produce production reports automatically as needed.
\end{abstract}

Keywords: Information Systems, Management, Scheduling, Production, Earliest Due Date

\section{PENDAHULUAN}

Sistem informasi (SI) dapat membantu segala jenis bisnis untuk meningkatkan efisiensi dan efektivitas proses bisnis, pengambilan keputusan manajerial, dan kerja sama kelompok kerja, hingga dapat memperkuat posisi kompetitif perusahaan dalam pasar yang cepat sekali berubah (O'Brien \& Marakas, 2011). Manajemen produksi dan operasi merupakan usaha-usaha pengelolaan secara optimal penggunaan sumber daya yang terdiri dari tenaga kerja, mesin, peralatan, bahan mentah dan sebagainya. Manajer produksi dan operasi mengarahkan berbagai masukan agar dapat memproduksi berbagai keluaran atau hasil

Received November 23, 2019; Revised November 29, 2019; Accepted Desember 12, 2019 
dalam jumlah, kualitas, harga, waktu dan tempat tertentu sesuai dengan permintaan konsumen untuk mencapai itu, diperlukan adanya penjadwalan agar output yang dihasilkan dapat diselesaikan sesuai target. Penjadwalan merupakan pengurutan atau pengerjaan produk secara menyeluruh yang dikerjakan pada beberapa buah mesin. Dengan demikian masalah urutan senantiasa melibatkan pengerjaan sejumlah komponen yang sering disebut dengan istilah "job". Job merupakan komposisi dari sejumlah elemenelemen dasar yang disebut aktivitas atau operasi. Tiap aktivitas atau operasi ini membutuhkan alokasi sumber daya tertentu selama periode waktu tertentu yang disebut dengan waktu proses, oleh karenanya dengan adanya penjadwalan produksi yang baik perusahaan tidak mengalami keterlambatan.

Pengelolaan produksi dan pesanan pelanggan saat ini masih sederhana, selain itu status persediaan bahan baku yang tidak dapat diketahui secara langsung seringkali dapat mengakibatkan keterlambatan proses produksi bahkan produksi tidak dapat dilakukan sesegera mungkin. Penjadwalan pesanan yang masuk menggunakan sistem first in first out dimana pesanan yang pertama datang yang dikerjakan, namun belum mempertimbangkan jumlah pesanan, prioritas pelanggan, jatuh tempo pengerjaan dan kapasitas mesin sehingga tidak dapat diketahui estimasi selesainya pesanan. Faktor lain penyebab keterlambatan adalah kerusakan mesin produksi dan sumber daya manusia yang berkaitan langsung dengan proses produksi. Hal tersebut menyebabkan proses penyelesaian barang membutuhkan waktu tunggu yang lama yang pada akhirnya terjadi keterlambatan dalam menyelesaikan produksi dan menerima kerugian serta komplain dari pelanggan.

Tabel 1. Daftar Antrian Produksi

\begin{tabular}{|l|l|l|l|l|l|}
\hline $\begin{array}{c}\text { Mesin } \\
\text { No. }\end{array}$ & \multicolumn{1}{|c|}{ Produksi } & Cavity & Banyaknya & Order Masuk & $\begin{array}{c}\text { Deadline } \\
\text { Produksi }\end{array}$ \\
\hline 1 & BotolShampo & 2 & $5.000 \mathrm{set}$ & $03 / 04 / 2017$ & $15 / 04 / 2017$ \\
\hline 2 & Botol $500 \mathrm{ml}$ & 2 & $10.000 \mathrm{set}$ & $05 / 04 / 2017$ & $26 / 04 / 2017$ \\
\hline 3 & Icepack Besar & 1 & $1.500 \mathrm{set}$ & $11 / 04 / 2017$ & $25 / 04 / 2017$ \\
\hline 4 & Tabung Olie & 1 & $4.500 \mathrm{set}$ & $14 / 04 / 2017$ & $24 / 04 / 2017$ \\
\hline 5 & Tabung Kanebo & 1 & $5.500 \mathrm{set}$ & $17 / 04 / 2017$ & $24 / 04 / 2017$ \\
\hline 6 & Jerigen 5 Liter & 1 & $3.000 \mathrm{set}$ & $20 / 04 / 2017$ & $27 / 04 / 2017$ \\
\hline Queue & Botol C30 & 2 & $1.000 \mathrm{set}$ & $20 / 04 / 2017$ & $22 / 04 / 2017$ \\
\hline Queue & Jerigen $250 \mathrm{ml}$ & 2 & $500 \mathrm{set}$ & $22 / 04 / 2017$ & $24 / 04 / 2017$ \\
\hline Quеие & Botol $100 \mathrm{ml}$ & 2 & $500 \mathrm{set}$ & $23 / 04 / 2017$ & $26 / 04 / 2017$ \\
\hline
\end{tabular}

Keterlambatan penyelesaian barang dari perusahaan diakibatkan karena belum adanya optimalisasi pengolahan dan pengelolaan data pesanan yang masuk pada perusahaan yang masih dilakukan secara konvensional dan sistem first in first out (pesanan yang pertama datang yang dikerjakan). Perusahaan tidak melihat pada jumlah pesanan, status prioritas pelanggan, jatuh tempo pengerjaan dan kapasitas mesin, sehingga menyebabkan pesanan belum terkelola dengan baik. Keterlambatan itu terjadi karena ketidaktahuan informasi untuk pesanan mana yang harus dikerjakan terlebih dahulun sehingga menimbulkan antrian dan waktu tunggu yang lama, serta berdampak pada jadwal kerja produksi yang terlambat.

Untuk mengatasi permasalah tersebut, diperlukan sebuah sistem yang dapat membantu perusahaan CV. Maju Plastik Semarang dalam mengatur serta mengelola data pesanan ataupun produksi pada perusahaan terebut. Selain itu, sistem ini diharapkan dapat mengatur penjadwalan produksi yang selama ini dirasa masih kurang baik menjadi lebih efisien dan terarah dengan diterapkannya metode yang baru yaitu menggunakan Earliest Due Date dengan mengurutkan pekerjaan-pekerjaan berdasarkan tanggal jatuh tempo (due date) yang terdekat, Metode ini dapat digunakan untuk penjadwalan pada satu mesin (single machine) maupun untuk penjadwalan pada beberapa mesin (paralel machine). Metode Earliest Due Date (EDD) mengurutkan pekerjaan-pekerjaan berdasarkan tanggal jatuh tempo (due date) yang terdekat. Metode dapat digunakan untuk penjadwalan pada satu mesin (single machine) maupun untuk penjadwalan pada beberapa mesin (paralel machine). Dalam prosedur jatuh tempo, pekerjaan diurutkan berdasarkan jatuh tempo terdekat atau berdasarkan tugas-tugas yang mempunyai tanggal dibutuhkan paling cepat. Prosedur jatuh tempo meminimalkan keterlambatan (tardiness) maksimum. Parameter-parameter yang diperlukan dalam penjadwalan dengan metode Earliest Due Date (EDD) ini adalah waktu pemroses dan due date tiap pekerjaan. Langkah-langkah penggunaan metode ini yaitu (1) urutkan pekerjaan berdasarkan tanggal jatuh tempo terdekat. (2) Ambil pekerjaan satu persatu dari urutan berdasarkan tanggal jatuh tempo untuk jadwalkan pada mesin dengan beban yang paling minimum. 


\section{TINJAUAN PUSTAKA}

2.1. Manajemen Produksi atau Operasi

Menurut Heizer \& Render (2011:4) bahwa Manajemen Operasi adalah serangkaian aktivitas yang menghasilkan nilai dalam bentuk barang dan jasa dengan mengubah input menjadi output. Selanjutnya menurut Stevenson (2014) manajemen operasi (operations management) adalah manajemen sistem atau proses yang menciptakan barang dan menyediakan jasa. Berdasarkan definisi manajemen operasi oleh para ahli diatas, dapat disimpulkan bahwa manajemen operasional adalah kegiatan yang berhubungan dengan perencanaan, pengkoordinasian, penggerakan dan pengendalian aktivitas organisasi atau perusahaan bisnis atau jasa yang berhubungan dengan proses pengolahan input menjadi output dengan nilai tambah yang besar.

2.2. Earliest Due Date (EDD)

Metode Earliest Due Date (EDD) mengurutkan pekerjaan-pekerjaan berdasarkan tanggal jatuh tempo (due date) yang terdekat. Metode dapat digunakan untuk penjadwalan pada satu mesin (single machine) maupun untuk penjadwalan pada beberapa mesin (paralel machine). Metode penjadwalan yang menghasilkan maximum tardiness yang paling minimum adalah metode Earliest Due Date (Bedworth, 1987). Dalam prosedur jatuh tempo, pekerjaan diurutkan berdasarkan jatuh tempo terdekat atau berdasarkan tugas-tugas yang mempunyai tanggal dibutuhkan paling cepat. Prosedur jatuh tempo meminimalkan keterlambatan (tardiness) maksimum. Parameter-parameter yang diperlukan dalam penjadwalan dengan metode Earliest Due Date (EDD) ini adalah waktu pemroses dan due date tiap pekerjaan. Langkah-langkah penggunaan metode ini antara lain :

Langkah 1 : Urutkan pekerjaan berdasarkan tanggal jatuh tempo terdekat.

Langkah 2 : Ambil pekerjaan satu persatu dari urutan berdasarkan tanggal jatuh tempo itu lalu jadwalkan pada mesin dengan beban yang paling minimum.

2.3. Unified Modeling Language

Menurut Rosa A.S (2013:133) Unified Modeling Language (UML) adalah salah satu standar bahasa yang digunakan didunia industri untuk mendefinisikan requirement, membuat analisis dan desai, serta menggambarkan arsitektur dalam pemrograman berorientasi objek. UML juga merupakan bahasa visual untuk permodelan dan komunikasi mengenai sebuah sistem dengan menggunakan diagram dan teksteks pendukung. UML hanya berfungsi untuk melakukan permodelan. Unified Modeling Language (UML) memiliki beberapa diagram untuk membuat suatu model.

2.4. Penelitian Terdahulu

Penelitian sejenis pernah dilakukan oleh Riwan Tri Haryono, Siska Iriani pada tahun 2013 tentang Perancangan Sistem Informasi Pengolahan Data Produksi dan Penjualan Pada Pabrik Penggergajian Batu CV. Bumi Indah Persada. Sistem yang dibangun menggunakan bahasa pemrograman Java dan MySQL sebagai database yang menghasilkan sistem informasi pengolahan data produksi dan penjualan pada pabrik penggergajian batu CV. Bumi Indah Persada. Adanya sistem informasi pengolahan data produksi dan penjualan pada pabrik penggergajian CV. Bumi Indah Persada dapat mempermudah analisa sehingga perusahaan dapat dengan cepat menentukan langkah dan kebijakan dengan berdasarkan hasil laporan serta terorganisrnya setiap kegiatan dari pengadaan bahan baku, produksi dan penjualan perusahaan tersebut.

Penelitian sejenis juga pernah dilakukan olehYulianto, Setia Wardani, Wibawa pada tahun 2016 tentang Sistem Informasi Manajemen Produksi Unit Painting \& Packaging CV. Karya Hidup Sentosa Berbasis Web yang dibangun dengan menggunakan bahasa pemrograman PHP dan MySQL sebagai database yang menghasilkan sistem informasi manajemen produksi unit painting \& packaging CV. Karya Hidup Sentosa. Adanya sistem informasi manajemen produksi unit painting \& packaging pada CV. Karya Hidup Sentosa dapat meminimalisir data stok komponen produksi, dapat menyajikan data stok komponen produksi secara realtime, mempermudah kontrol stok komponen produksi dan mengurangi jumlah pemakaian dokumen kertas laporan (paperless).

\section{METODE PENGEMBANGAN}

Metode pengembangan sistem yang digunakan dalam penelitian perancangan sistem informasi manajemen berbasis web adalah dengan menggunakan metode Software Development Life Cycle (SDLC) dengan tahapan - tahapan sebagai berikut :

1. Tahap Perencanaan adalah mengidentifikasi permasalahan yang terjadi pada CV. Maju Plastik seperti : Sistem pengelolaan data pesanan produk yang masih menggunakan cara konvensional, dengan cara menulis data pesanan dari pelanggan pada papan tulis dan memberikan data hasil produksi secara

ELKOM Vol. 12, No. 2, Desember 2019: $72-83$ 
lisan, Sering terjadinya keterlambatan proses produksi dikarenakan belum adanya sistem penjadwalan produksi, Kendala lainnya yaitu dalam pendataan hasil produksi belum tersistem sehingga data hasil produksi tidak dapat diketahui secara akurat.

2. Tahap analisa diawali dengan kegiatan mendefinisikan kebutuhan data dan informasi yang dibutuhkan untuk merancang sistem informasi manajemen produksi. Data yang yang dibutuhkan dalam penelitian ini adalah jumlah order yang masuk dari pelanggan, jumlah mesin yang tersedia untuk melakukan proses produksi. Kemudian informasi yang dihasilkan dalam penelitian ini adalah informasi mengenai order yang masuk dari pelanggan, seperti nama pelanggan, barang yang di order, dan jumlah barang yang di order, informasi mengenai penjadwalan produksi, informasi mengenai laporan produksi rutin pada setiap harinya.

3. Tahap perancangan sistem kegiatan yang dilakukan yaitu membuat pemodelan proses, pemodelan data, dan membuat desain tampilan antar muka (interface).

a) Pemodelan Proses. Pemodelan proses sistem perencanaan kebutuhan bahan baku secara garis besar dibagi menjadi tahap bisnis use case yang menerangkan secara garis besar aktor yang terlibat dalam sistem, sedangkan sistem use case merupakan gambaran lebih detil tentang apa yang dilakukan oleh aktor di dalam sistem informasi manajemen produksi.

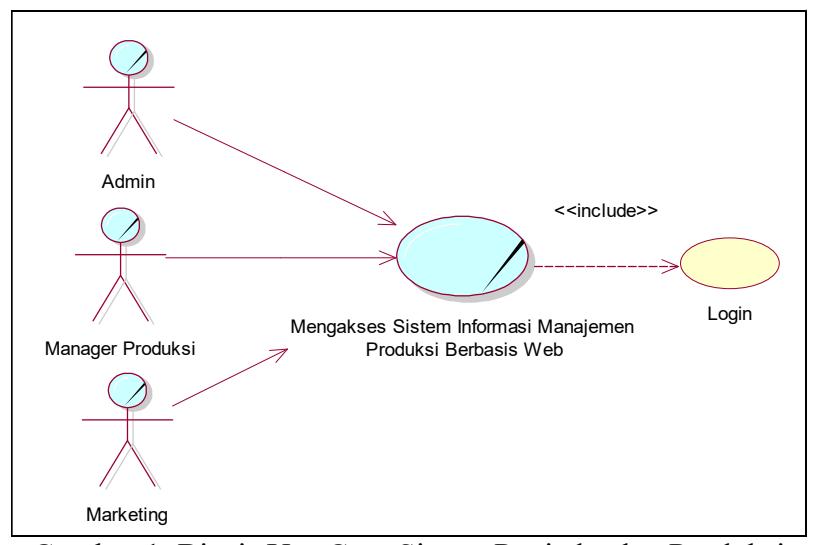

Gambar 1. Bisnis Use Case Sistem Penjadwalan Produksi

b) Sistem informasi manajemen produksi yang akan dikembangkan mempunyai 3 Aktor yang terlibat dalam sistem informasi manajemen produksi pada CV. Maju Plastik yaitu admin, Marketing, dan manajer produksi. Pada usulan sistem baru ini aktor memerlukan login ketika akan berinteraksi dengan sistem seperti pada gambar 1.

c) Diagram sistem use case ini menjelaskan bahwa manajer produksi dapat menggunakan sistem melalui login terlebih dahulu. Agar dapat melakukan penambahan rencana produksi, menambah data hasil produksi, mengentikan rencana produksi, mengelola produksi, melihat daftar produksi dan laporan data hasil produksi, seperti yang pada gambar 2.

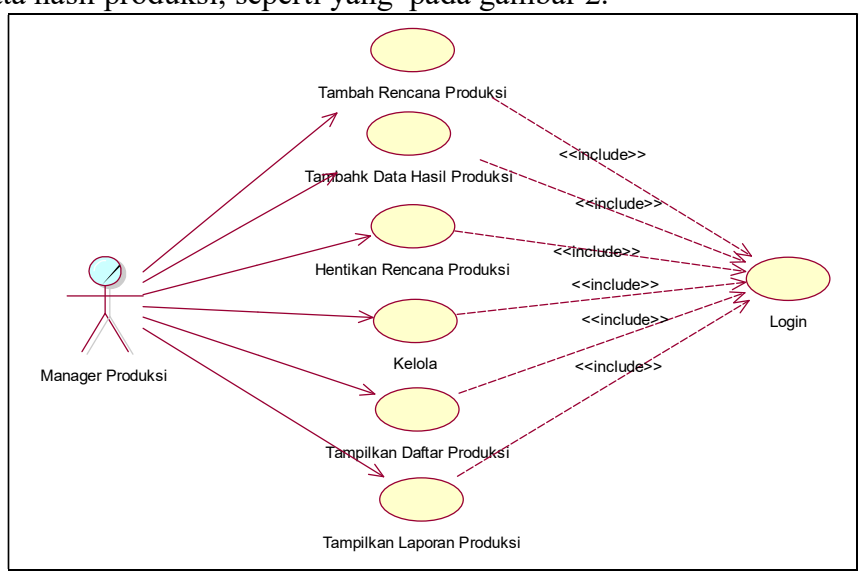


d) Gambar 2. Diagram Sistem Usecase Manager Produksi

e) Diagram sistem use case ini menjelaskan bahwa admin dapat masuk kedalam sistem setelah melakukan login terlebih dahulu, agar dapat melakukan hal seperti melihat data, menambah data, memperbarui data dan menghapus data seperti yang ditunjukkan pada gambar 3 .

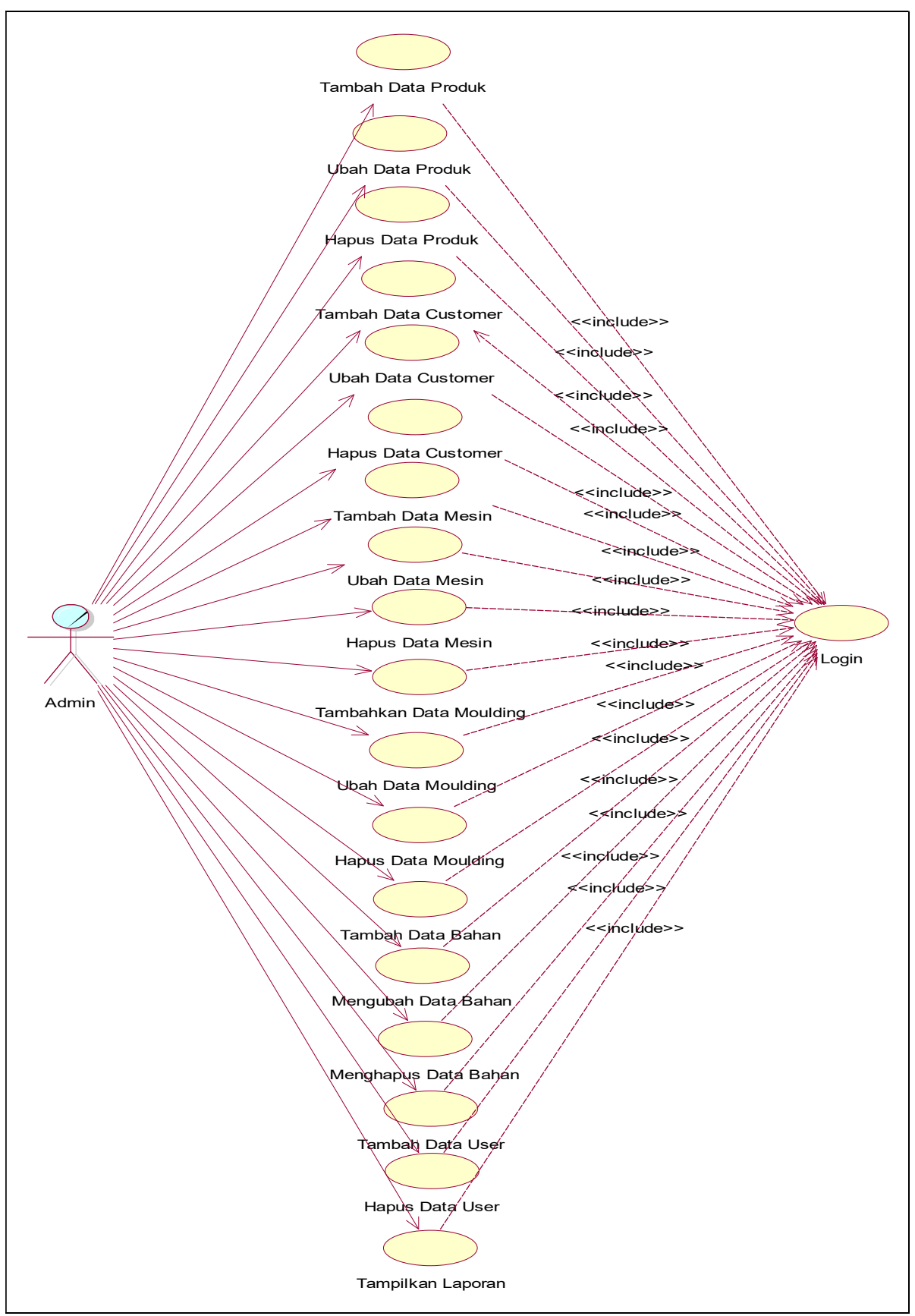

Gambar 3. Diagram Sistem Use Case Admin

Diagram sistem use case ini menjelaskan bahwa staff marketing dapat masuk kedalam sistem setelah melakukan login terlebih dahulu, agar dapat melakukan hal seperti menambah data order, melihat data order, mengubah data order, menghapus data order dan melihat laporan, seperti yang pada gambar 4 . 


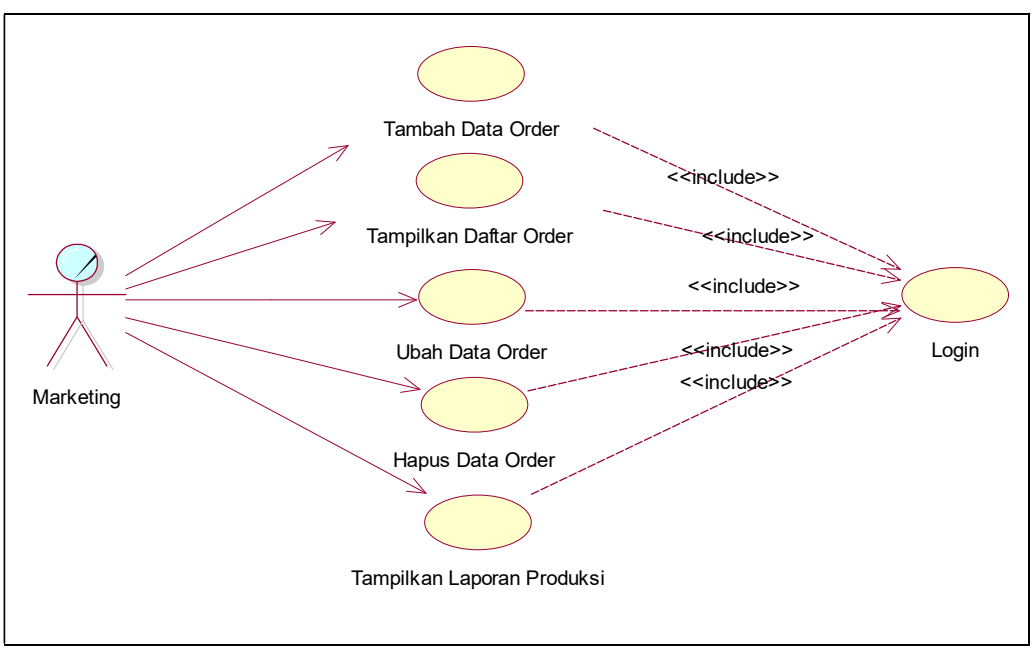

Gambar 4. Diagram Sistem Usecase Marketing

b. Pemodelan Data. Pemodelan data pada sistem informasi manajemen produksi meliputi penggambaran entity relationship diagram, merancang tabel-tabel yang dibutuhkan pada database, dan membuat relasi antar tabel. Entity Relationship yang dibuat memiliki keterkaitan antara data yang satu dengan data yang lainnya. Tabel-tabel yang telah dirancang kemudian direalisasikan antara tabel satu dengan yang lain untuk mendukung kelancaran pengolahan data. Gambar 5 merupakan hubungan antar tabel yang saling berelasi.

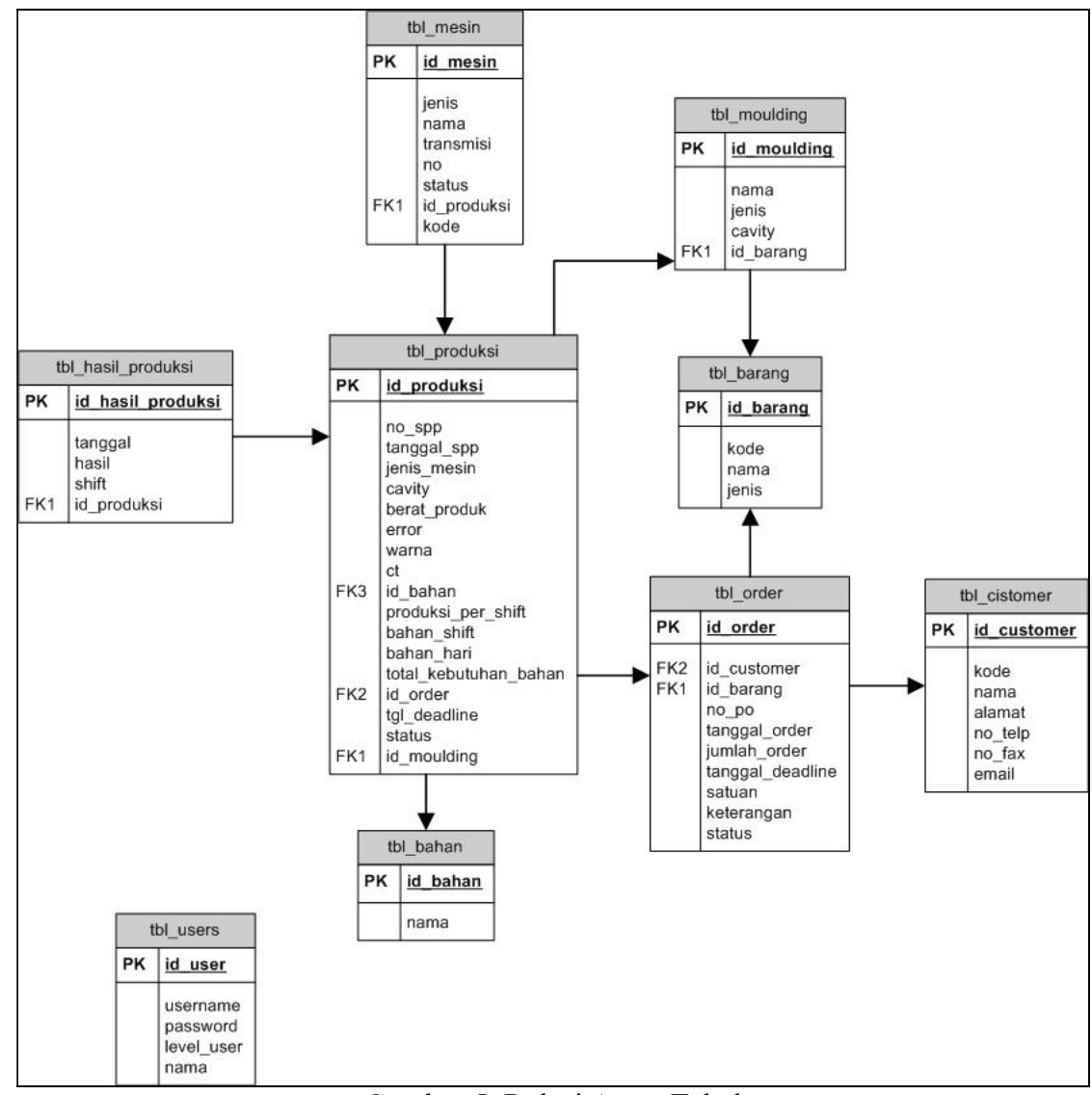

Gambar 5. Relasi Antar Tabel 
c. Rancangan antarmuka, rancangan antarmuka aplikasi digunakan untuk memberikan gambaran mengenai sistem informasi manajemen produksi. Rancangan antar muka input order merupakan rancangan yang dapat digunakan oleh staff marketing untuk menambahkan data order dari customer untuk diproduksi. Halaman ini terdapat form yang berfungsi untuk menyimpan order yang masuk dari customer. Rancangan input order ditunjukkan pada gambar 6.

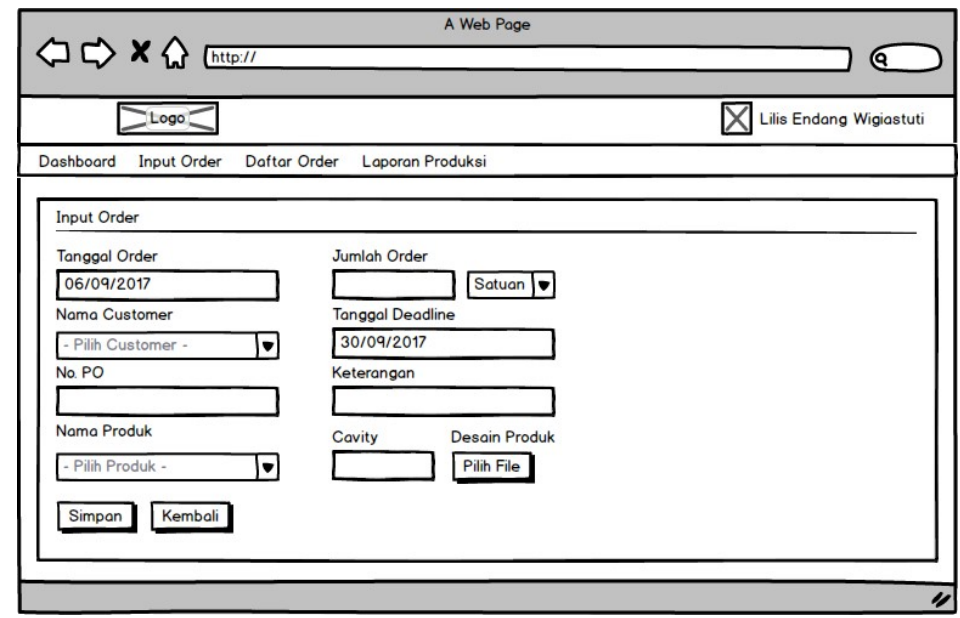

Gambar 6. Desain Halaman Input Order

Rancangan antar mukabuat rencana produksi merupakan halaman yang dapat digunakan oleh manajer untuk mengelola data order produksi yang masuk. Halaman ini terdapat form yang digunakan untuk mencatat perencanaan produksi.

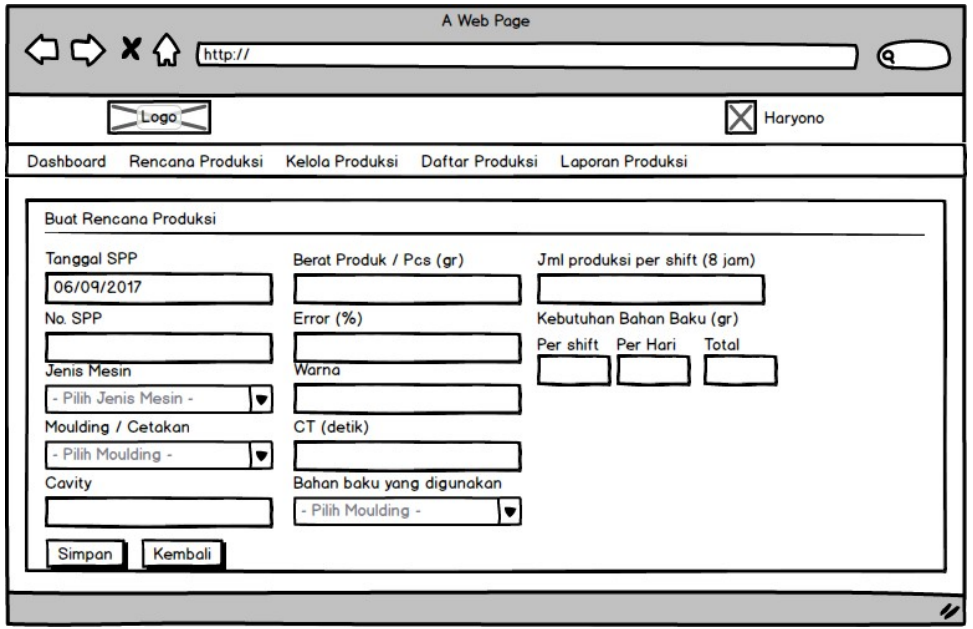

Gambar 7. Desain Halaman Buat Rencana Produksi

d. Implementasi sistem, Perangkat keras yang diperlukan untuk mengembangkan Sistem Informasi Manajemen Produksi Hardware sebagai server bagi sistem. Hardware sebuah computer dengan spesifikasi Processor Intel Dual Core $2.6 \mathrm{Ghz}$, memory RAM DDR $34 \mathrm{~Gb}$, harddisk $100 \mathrm{~Gb}$, Hardware bagi manajer produksi CV. Maju Plastik. Hardware sebuah PC Desktop dengan spesifikasi Processor Intel Dual Core $2.6 \mathrm{Ghz}$, memory RAM DDR $32 \mathrm{~Gb}$, harddisk $250 \mathrm{~Gb}$. Software yang digunakan yaitu PHP sebagai bahasa program, MySQL Server sebagai database dan editor kode menggunakan Sublime Text 3. Metode Pengujian yang digunakan adalah pengujian kotak hitam (black box testing) yaitu dengan cara memberi input dari pengguna kepada sistem yang sudah berjalan dan mengamati hasil output dari sistem.

ELKOM Vol. 12, No. 2, Desember 2019: $72-83$ 


\section{HASIL DAN PEMBAHASAN}

4.1 Hasil Pengembanganan Sistem

Halaman ini digunakan staff marketing untuk memasukkan atau mencatat data order yang masuk dari customer, seperti yang ditunjukkan pada gambar 8 .

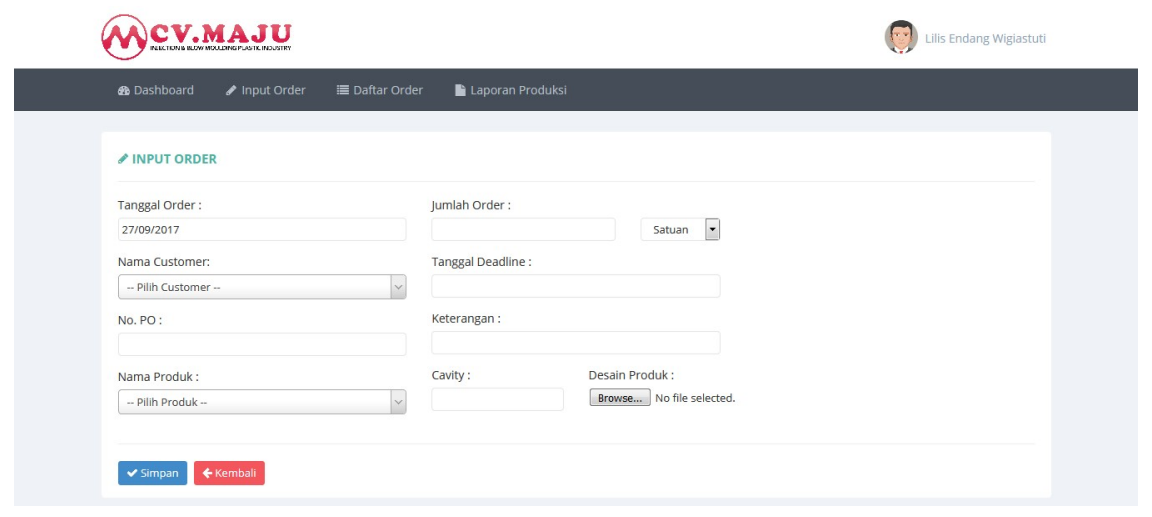

Gambar 8. Halaman Input Order

Pada halaman ini staff marketing dapat mengubah, menghapus serta melihat status pengerjaan order customer, seperti yang ditunjukkan pada gambar 9.

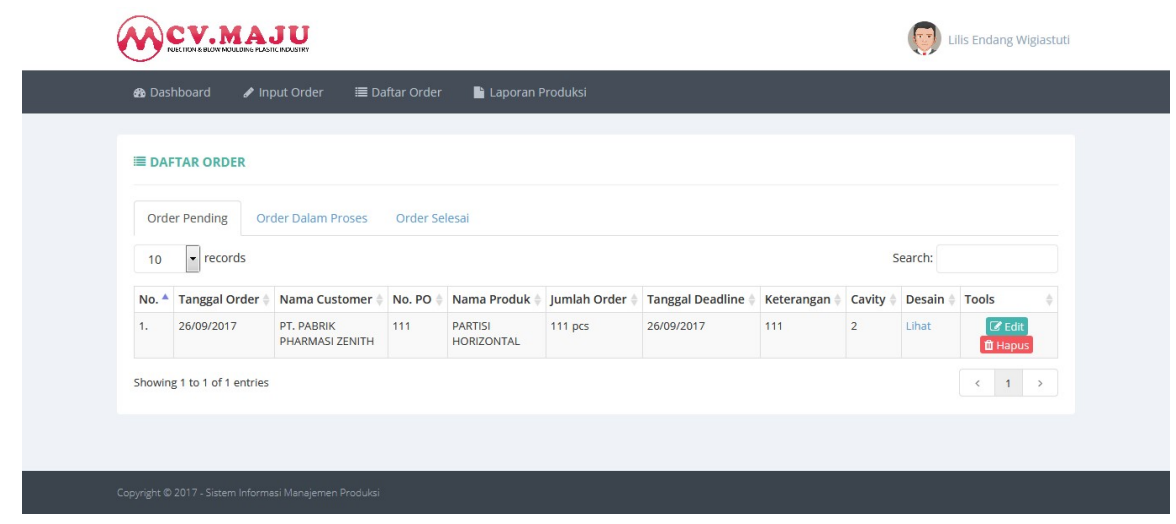

Gambar 9. Daftar Order

Pada halaman ini manajer produksi dapat membuat perencanaan produksi yang berdasarkan dari order yang masuk, seperti yang ditunjukkan pada gambar 10 .

(M) CV.MAJU

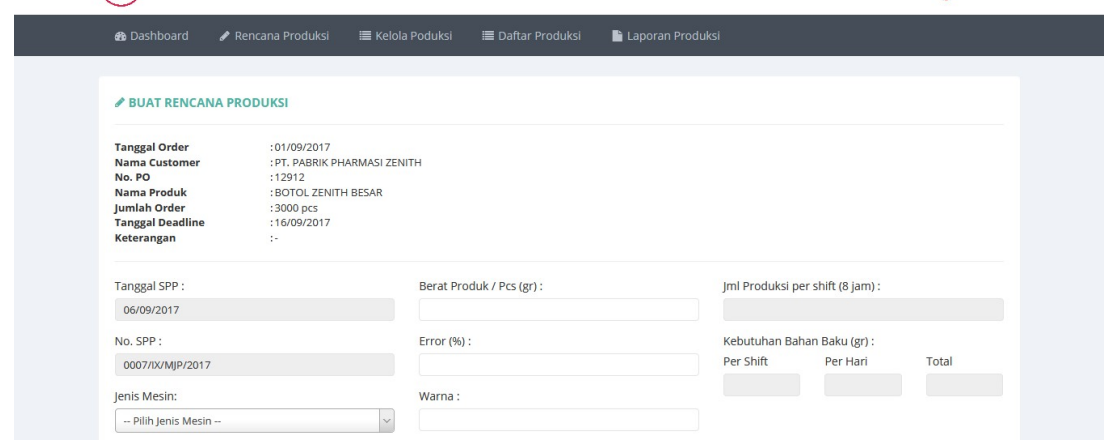


Gambar 10. Halaman Buat Rencana Produksi

Pada halaman kelola produksi manajer dapat memilih mesin mana siap untuk melakukan proses produksi dengan melihat status kesiapan dari tiap tiap mesin, seperti yang ditunjukkan pada gambar 11.

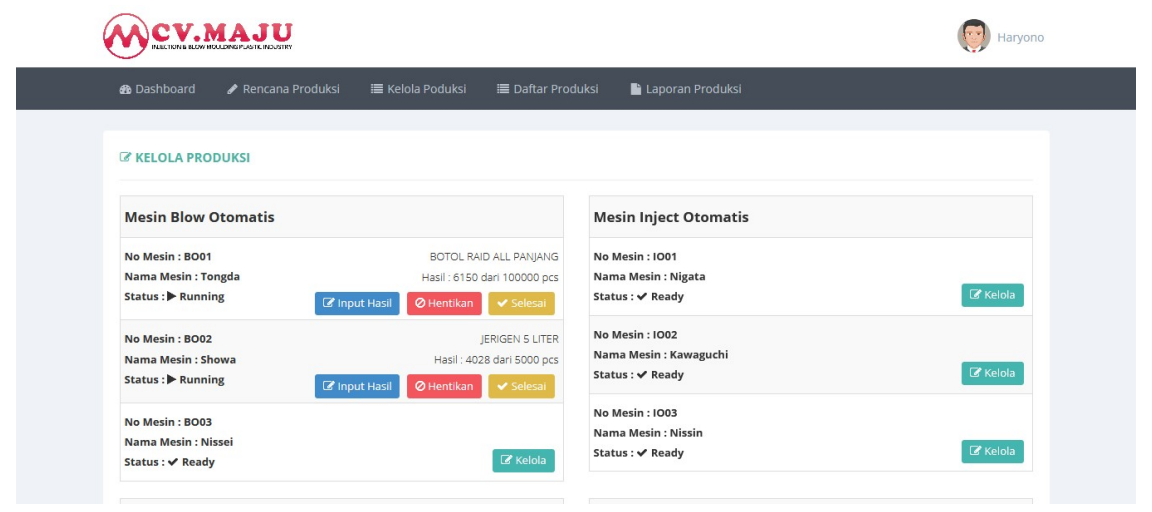

Gambar 11. Halaman Kelola Produksi

Pada halaman ini manajer produksi dapat melihat dan mengetahui produk apa saja yang sedang diproduksi, atau mesin manakah yang sedang berjalan, seperti yang ditunjukkan pada gambar 12 .

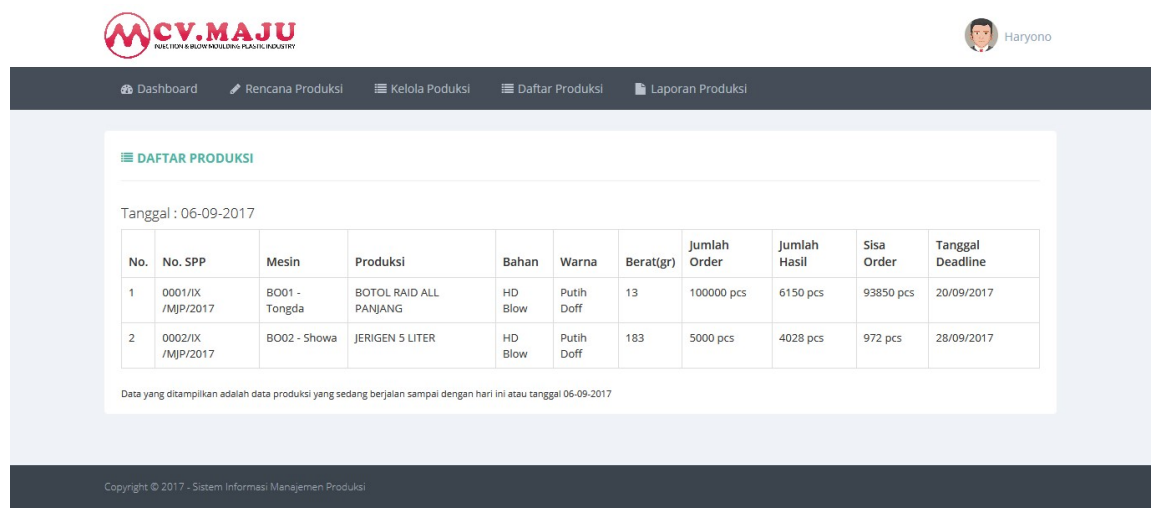

Gambar 12. Daftar Produksi

Pada halaman laporan manajer dapat melihat data laporan produksi, laporan order ataupun laporan penggunaan bahan, seperti yang ditunjukkan pada gambar 13.

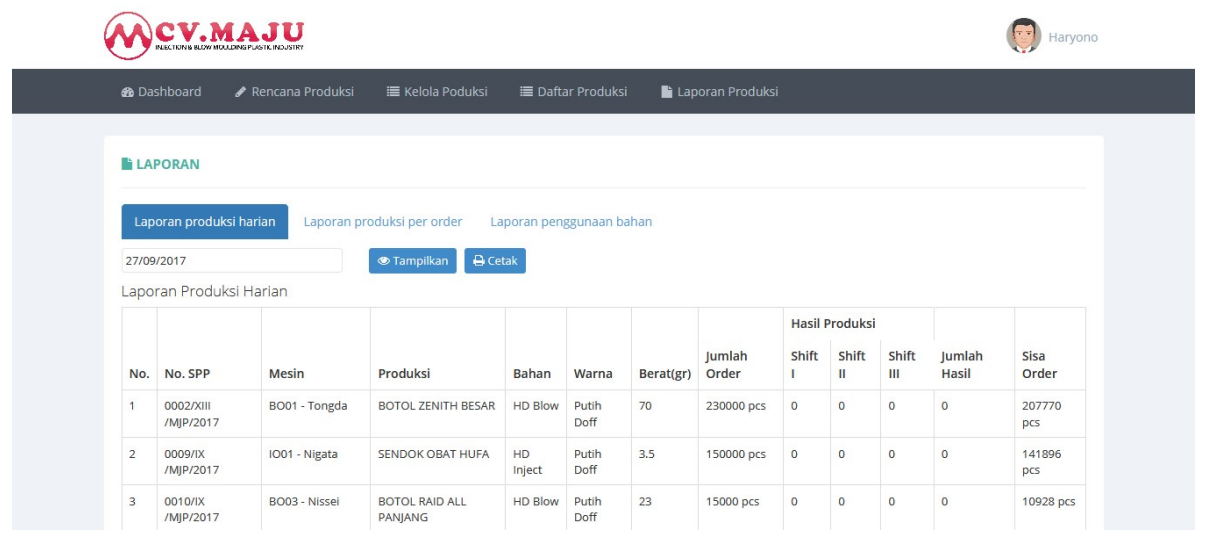

Gambar 13. Halaman Laporan 


\subsection{Pengujian Sistem}

Metode pengujian yang digunakan dalam pengujian sistem informasi manajemen produksi berbasis web ini adalah menggunakan black box. Daftar use case, metode pengujian serta kriteria evaluasi hasil pengujian dapat dilihat pada tabel 2.

\begin{tabular}{|c|c|c|c|c|c|}
\hline $\begin{array}{c}\text { Id } \\
\text { Kasus } \\
\text { Uji }\end{array}$ & $\begin{array}{l}\text { Prosedur } \\
\text { Pengujian }\end{array}$ & Input Pengujian & $\begin{array}{l}\text { Output yang } \\
\text { Diharapkan }\end{array}$ & $\begin{array}{c}\text { Hasil } \\
\text { yang } \\
\text { Diperoleh }\end{array}$ & $\begin{array}{c}\text { Kesimp } \\
\text { ulan }\end{array}$ \\
\hline \multirow[t]{2}{*}{ UC-1 } & $\begin{array}{l}\text { Admin } \\
\text { melakukan } \\
\text { login }\end{array}$ & $\begin{array}{l}\text { Admin memasukkan } \\
\text { username dan password }\end{array}$ & Login berhasil & $\begin{array}{l}\text { Sesuai } \\
\text { harapan }\end{array}$ & Berhasil \\
\hline & $\begin{array}{l}\text { Kegiatan } \\
\text { Admin }\end{array}$ & Mengelola data master & Data master bertambah & $\begin{array}{l}\text { Sesuai } \\
\text { harapan }\end{array}$ & Berhasil \\
\hline \multirow[t]{5}{*}{ UC-2 } & $\begin{array}{l}\text { Manajer } \\
\text { melakukan } \\
\text { login }\end{array}$ & $\begin{array}{l}\text { Manajer memasukkan } \\
\text { username dan password }\end{array}$ & Login berhasil & $\begin{array}{l}\text { Sesuai } \\
\text { harapan }\end{array}$ & Berhasil \\
\hline & $\begin{array}{l}\text { Kegiatan } \\
\text { Manajer }\end{array}$ & $\begin{array}{l}\text { Menambah rencana } \\
\text { produksi }\end{array}$ & $\begin{array}{l}\text { Rencana produksi } \\
\text { bertambah }\end{array}$ & $\begin{array}{l}\text { Sesuai } \\
\text { harapan }\end{array}$ & Berhasil \\
\hline & $\begin{array}{l}\text { Kegiatan } \\
\text { Manajer }\end{array}$ & Mengelola produksi & Data produksi terkelola & $\begin{array}{l}\text { Sesuai } \\
\text { harapan }\end{array}$ & Berhasil \\
\hline & $\begin{array}{l}\text { Kegiatan } \\
\text { Manajer }\end{array}$ & Melihat daftar produksi & Data produksi tampil & $\begin{array}{l}\text { Sesuai } \\
\text { harapan }\end{array}$ & Berhasil \\
\hline & $\begin{array}{l}\text { Kegiatan } \\
\text { Manajer }\end{array}$ & Mencari data laporan & $\begin{array}{l}\text { Data laporan produksi } \\
\text { tampil }\end{array}$ & $\begin{array}{l}\text { Sesuai } \\
\text { harapan }\end{array}$ & Berhasil \\
\hline \multirow[t]{5}{*}{ UC-3 } & $\begin{array}{l}\text { Marketing } \\
\text { melakukan } \\
\text { login }\end{array}$ & $\begin{array}{l}\text { Marketing memasukkan } \\
\text { username dan password }\end{array}$ & Login berhasil & $\begin{array}{l}\text { Sesuai } \\
\text { harapan }\end{array}$ & Berhasil \\
\hline & $\begin{array}{l}\text { Kegiatan } \\
\text { Marketing }\end{array}$ & Menambah data order & Data order bertambah & $\begin{array}{l}\text { Sesuai } \\
\text { harapan }\end{array}$ & Berhasil \\
\hline & & Mengubah data order & Data order diperbarui & $\begin{array}{l}\text { Sesuai } \\
\text { harapan }\end{array}$ & Berhasil \\
\hline & & Menghapus data order & Data order terhapus & $\begin{array}{l}\text { Sesuai } \\
\text { harapan }\end{array}$ & Berhasil \\
\hline & $\begin{array}{l}\text { Kegiatan } \\
\text { Marketing }\end{array}$ & Mencari data laporan & $\begin{array}{l}\text { Data laporan produksi } \\
\text { tampil }\end{array}$ & $\begin{array}{l}\text { Sesuai } \\
\text { harapan }\end{array}$ & Berhasil \\
\hline
\end{tabular}

\subsection{Pembahasan}

Berdasarkan simulasi sistem informasi manajemen produksi berbasis web pada CV. Maju Plastik selanjutnya dilakukan pembahasan terhadap sistem yang berjalan. Pembahasan ini dilakukan dengan melihat hubungan sistem dengan kebutuhan pengguna terhadap informasi yang didapat. Hasil pembahasan meliputi diantaranya :

1. Perancangan Sistem

Sistem informasi manajemen produksi berbasis web dengan bahasa pemrograman PHP dan MySQL ini dirancang menggunakan metode System Development Life Cycle. Dibutuhkan beberapa data untuk merancang sistem ini diantaranya adalah data produk, data customer, data mesin, data bahan baku, data order, data produksi, dan data laporan. Sistem ini melibatkan tiga aktor yaitu admin, manajer produksi, dan staff marketing. Admin bertanggung jawab dalam sistem ini memiliki beberapa bisnis usecase seperti mengelola data produk, mengelola data customer, data mesin, mengelola data moulding, mengelola data bahan, mengelola data user dan laporan. Manajer produksi dapat mengelola rencana produksi, melakukan pengelolaan data produksi, mengelola daftar produksi dan melihat laporan. Sedangkan staff marketing dapat mengelola menambahkan order masuk dari customer, melihat dan mengubah status data order dari customer dan melihat laporan produksi.

2. Implementasi Sistem

Sistem informasi manajemen produksi berbasis web pada CV. Maju Plastik Semarang sangat membantu dalam proses pengelolaan data produksi. Dengan cara melalui web dalam koneksi local 
dapat membantu serta staff marketing dalam pencatatan data order produksi dari customer tanpa harus takut kehilangan data atau data order tidak tercatat dengan baik, selain itu staff marketing juga dapat secara mudah melihat data hasil produksi yang sedang berjalan sehingga staff marketing tidak mengalami kesulitan ketika customer menanyakan status order milik customer tersebut. Sistem ini juga mempermudah manajer produksi dalam melakukan perencanaan produksi, manajer produksi tidak perlu lagi repot melihat order yang masuk pada papan tulis yang memang lokasinya berada jauh dari meja kerja manajer produksi. Dengan ini membuktikan bahwa manajer produksi dapat melakukan pengelolaan data produksi dengan mudah.

Implementasi yang dilakukan masih dalam tahap pengujian alfa yaitu Sistem Informasi Manajemen Produksi diuji sendiri oleh penulis meliputi data order, dan data produksi melalui web.

\section{KESIMPULAN}

Kesimpulan yang didapat penulis dalam penelitian ini adalah :

1. Sistem informasi manajemen produksi berbasis web ini dirancang dengan menggunakan bahasa pemrograman PHP dan MySQL sebagai database-nya. Sistem ini memiliki tiga aktor utama yaitu pimpinan selaku admin, staff marketing, dan manajer produksi.

2. Adanya sistem informasi manajemen produksi berbasis web ini dapat digunakan oleh manajer produksi dalam melakukan perencanaan dan pengelolaan data produksi serta membantu dalam pencatatan data produksi pada CV. Maju Plastik. Sistem informasi manajemen produksi berbasis web ini juga memudahkan pelaku bisnis dalam hal ini adalah manajer produksi dalam penyampaian hasil dan laporan produksi kepada marketing sehingga dari pihak marketing sendiripun dapat mengetahui secara mudah hasil produksi dari order customer yang sedang diproduksi pada CV. Maju Plastik.

ELKOM Vol. 12, No. 2, Desember 2019: $72-83$ 


\section{DAFTAR PUSTAKA}

[1] Bedworth, D. D., Bailey, J.E. 1987. Integrated Production Control Systems : Management, Analysis, Design, 2 ed. John Wiley \& Sons, Inc: New York.

[2] Bistami Bastian, Nurlela. 2010. Akuntansi Biaya. Yogyakarta : Graha Ilmu.

[3] Ely Suhayati, Sri Dewi Anggadini. 2009. Akuntansi Keuangan, Edisi Pertama. Yogyakarta: Graha Ilmu.

[4] Haryono, Riwan \& Iriani Siska. 2013. Perancangan Sistem Informasi Pengolahan Data Produksi Dan Penjualan Pada Pabrik Penggergajian Batu CV. Bumi Indah Persada. Indonesian Journal on Networking and Security. [5] Sugiono, Metode Penelitian Pendidikan. Bandung: Alfabeta, 2016.

[5] Heizer, Jay \& Barry Render. 2011. Operations Management, Buku 1 Edisi ke 9. Jakarta: Penerbit Salemba Empat.

[6] Stevenson, William, J. 2014. Manajemen Operasi: Perspektif Asia. Buku 1, Edisi 9. Jakarta : Penerbit Salemba Empat.

[7] Trenggonowati. 2011. Teori Akuntansi Mikro, Edisi 2. Yogyakarta. BPFE.

[8] Yulianto, dkk. 2016. Sistem Informasi Manajemen Produksi Unit Painting \& Packaging CV. Karya Hidup Sentosa Berbasis Web. Jurnal Dinamika Informatika. Volume 5 No 2. 